\title{
СИСТЕМНАЯ ОНТОЛОГИЯ
}

Аннотация. Используемый автором системный подход преодолевает ограниченность изолированного рассмотрения онтологии. Онтология, понимаемая как учение о единстве мира, рассматривается как часть господствующей в обществе системы представлений во взаимосвязи с развитием индивида - с одной стороны и с общественной практикой - сдругой.

Ключевые слова: философия, онтология, бытие, истина, дуализм, линейность, адекватность, мировоззрение, система, единство.

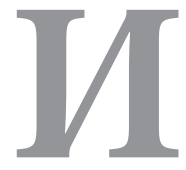

зложенный в настоящей статье взгляд на онтологию является результатом применения методологии системного подхода, о качестве и эффективности которой позволяют судить полученные при этом результаты.

Современная онтология, сохраняя преемственность с буквальным переводом этого слова с древнегреческого, как "учения о бытии», игнорирует содержание, которое ее основатель, Аристотель, вкладывал в категории бытия, сущего и в саму онтологию. Аристотель опирается на категории бытия и сущего, решая вопрос обоснования единства мира через общую основу, считая, что «наиболее достойны познания первоначала и причины, ибо через них и на их основе познается все остальное, а не они через то, что им подчинено» ${ }^{1}$. У Аристотеля бытие и сущее соотносятся как возможность и действительность, и они не противопоставлены материальному миру, а являются основой его единства: «сущее и единое - одно и то же, и природа у них одна, поскольку они сопутствуют друг другу, как начало и причина» ${ }^{2}$. Выделение сущего и бытия, как основы единства мира, обуславливает и понимание процесса познания: «Ведь мы познаем все вещи постольку, поскольку у них имеется что-то единое и тождественное и поскольку им присуще нечто общее» ${ }^{3}$. У Аристотеля онтология - это учение о единстве

\footnotetext{
${ }^{1}$ Аристотель. Метафизика // Хрестоматия по западной философии: Античность. Средние века. Возрождение. М.: Астрель: АСТ, 2003. 800 с. С. 144.

2 Там же. С. 144.

${ }^{3}$ Там же. С. 141.
}

мира, как обоснование возможности его познания, в современной же западной философии - это учение о категории бытия, которая утратила значение обоснования единства, т.е. онтологический статус. Такая верность категории в ущерб содержанию приводит к снижению значения самой онтологии, что закономерно проявляется в провозглашении частью западной философии принципа «деонтологизации». Сведение онтологии к отдельной категории закономерно игнорирует развитие представлений о единстве мира, игнорирует развитие мышления, в процессе которого меняется понимание самой категории бытия.

Современные онтологические представления российской философии, большей частью, заимствованы в западной. Как выразился А. Р. Абдуллин: «особенностью российской философской онтологии является ее «вторичность» по отношению к западноевропейской. Иначе говоря, российская онтология по существу есть рефлексия над западной» ${ }^{4}$.Такое доминирование представлений западной философии сложилось как результат кризиса диалектического материализма в нашей стране. Однако в таком переходе от представлений марксизма - ленинизма к представлениям западной философии проявляется ограниченность линейного мышления, опирающегося на представление об абсолютности истины. В советской философии проявлялось явное абсолютизирование материализма, теперь происходит такое же абсолютизирование идеалистической кантовской традиции западной философии, для кото-

\footnotetext{
${ }^{4}$ Абдуллин А.Р. Онтологическое мышление: виды и сущность. Уфа: Изд-е Башкирск. ун-та, 2002. 481 с. С. 15.
} 


\section{Философия и культура 11(71) • 2013}

рой диалектика и материализм - это «обоснование тоталитаризма и большевизма» (К. Поппер). Этот уровень мышления еще Г.В.Ф. Гегель характеризовал как «догматический», полагающий, что из двух «противоположных утверждений» «одно должно быть истинным, другое - ложным» ${ }^{1}$. При этом необходимо учитывать плачевное состояние современной западной философии: кризис идеи «демаркации» в философии науки, полная бесплодность модернизма и постмодернизма, развитие неклассической философии прямо указывают на необходимость пересмотра исходных фундаментальных представлений, на которые западная философия опирается. Но другим свойством линейности мышления является авторитарность, которая не может без абсолютной истины, без «руководящих указаний», утратив одни, она сразу начинает искать другие. Эта характерная черта мышления проявилась и у части российских философов.

К примеру, А. Л. Доброхотов считает: «Онтологический метод предполагает, что открытая и изучаемая им реальность есть вне-природная действительность и совершенно автономная сфера универсума». При этом кантовское разделение «вне-природной действительности» и мира природы для него является совершенно неоспоримым и не требующим аргументации: «Естественно, что мысль или ряд мыслей существуют сами по себе, и вещь или ряд вещей - сами по себе. Эти два ряда не могут пересекаться в силу своей природы» ${ }^{2}$. Да и вряд ли такое утверждение сейчас можно хоть как-то внятно аргументировать.

Но, подключившись к обсуждению «мировых» проблем, российская философия проявляет не только авторитарность, но и самостоятельность мышления, отказываясь от противопоставления рационального и иррационального ${ }^{3}$, культуры и науки ${ }^{4}$, естественнонаучного знания и гуманитарного ${ }^{5}$. Между тем, такое противопоставление основано на кантовской традиции разделения «умопости-

\footnotetext{
${ }^{1}$ Гегель Г.В.Ф. Энциклопедия философских наук. Т. 1. Наука логики. М.: Мысль, 1974. 452 с. С. 138.

2 Доброхотов А.Л. Категория бытия в классической западноевропейской философии. М.: Изд-во Московского университета, 1986.

3 Исторические типы рациональности / Отв. ред. В. А. Лекторский. Т. 1. М., 1995. 350 с.

${ }^{4}$ Физика в системе культуры. / Отв. ред. Ю.В. Сачков. М., 1996. $231 \mathrm{c}$.

${ }^{5}$ Биофилософия / научн. рук. И. К. Лисеев, отв. ред. А. Т. Шаталов. М., 1997. 264 с.
}

гаемого мира» и «чувственно воспринимаемого», которая в западной философии остается незыблемой и считается не подлежащей пересмотру. Фактически значительная часть российской философии входит в противоречие с фундаментальными представлениями, господствующими в западной философии, демонстрируя более высокий уровень системности мышления.

Линейность мышления опирается на представление об абсолютности истины, находящейся вне человека и вне природы, что закономерно приводит к противопоставлению одной части реальности другой, как истинного и ложного. Ориентация на истину определяет конструкцию мышления, которое стремится не к полноте охвата любого явления, а к выделению одного главного свойства его «сущности». В этой конструкции мышления понимание человека закономерно строится на его отличии от природы и его близости к истине: через его разум, дух или через его особую телесную организацию и способность к производству «средств к жизни» (К. Маркс), через близость к трансцендентному Бытию (М. Хайдеггер) или через его единичное «существование» (С. Кьёркегор). Это закономерно проявляется в противопоставлении одной части реальности другой: человека и природы, разума и действительности, субъективного и объективного.

Линейность мышления может преодолеть разделение противоположностей только иерархически, как «первичное» и «вторичное», т.е. абсолютизирует как истину или «предельную категорию» одну из противоположностей, выстраивая иерархию представлений, в которой одна противоположность линейно, односторонне определяет другую, как причина - следствие, дух - природу, материя сознание, язык - мышление, или наоборот. Этот линейно-односторонний характер отношений не соответствует природе, в которой они всегда носят обоюдный характер взаимодействия, как проявление всеобщего характера взаимосвязей, поэтому линейность мышления закономерно проявляется в формировании представлений, которые носят характер редукционизма, неадекватности, идеологической ограниченности. Линейное мышление и не стремится к адекватности, оно стремится к трансцендентальной истине, отворачиваясь от реальности,- - неадекватность заложена в самой конструкции линейного мышления.

Выстраивая противоположные иерархии одних и тех же элементов линейное мышление закономерно формирует взаимоотрицающие представления, к примеру, о «первичности» сознания или материи, 


\section{Философия науки и образования}

личности или общества, приводит к неразрешимым противоречиям. Материалистическая идеология выстраивала иерархии: материи над сознанием, социализма над капитализмом, общества над личностью и т.д., противостоящая ей идеология западного общества до настоящего времени выстраивает иерархии: духа над природой, западной демократии над тоталитаризмом, индивидуальности над коллективом и т.д. Линейное мышление, ориентированное на истину, под единством понимает тождество и однородность, но не способно понять и осмыслить системное, диалектическое единство противоположностей, как их взаимосвязь и взаимообусловленность. Линейное мышление не способно создать целостную картину, как отдельного явления, так и мира в целом, оно анти - онтологично.

Концептуальным обоснованием принципа всеобщего характера взаимосвязей является общая теория системы природы ${ }^{1}$, на основе которой формируется системный подход, как проявление более адекватного реальности системного мышления. Его более высокий уровень по отношению к линейному мышлению проявляется в преодолении всяческого редукционизма, отрывочности и фрагментарности, в отказе от противопоставления одной части реальности другой, в рассмотрении человека, его развития, и природы в системном единстве и целостности. Системное мышление отличается онтологическим характером.

Системное рассмотрение человека как системы индивида в системе общества, являющегося активным элементом взаимодействия с природой, позволяет преодолеть ограниченность линейного мышления, проявляемого в изолированном рассмотрении онтологии. В этой цепи взаимосвязанных систем, взаимодействие мышления и представлений в системе разума - это не сфера отвлеченного умствования, это внутреннее качество индивида, определяющее его поведение, а господствующая в обществе система представлений - основа общественной практики и уровня взаимодействия с природой. Системное рассмотрение онтологии - это не только рассмотрение ее как части господствующей системы представлений во взаимосвязи с системой индивида - с одной стороны, и с изменением общественной практики и уровнем взаимодействия с природой - с другой. Это еще и понимание онтологических представлений, как проявления

\footnotetext{
${ }^{1}$ Шагиахметов М.Р. Основы системного мировоззрения. Системно-онтологическое обоснование. М.: КМК, 2009. $263 \mathrm{c}$.
}

уровня развития человека, который, выделившись из системы локального биогеоценоза, вступает во взаимодействие с природой в целом, проходя цикл формирования новой системы «человек и природа» через этапы: первобытного единства, через этапы зависимости и господства к диалектическому осознанному единству.

При этом выход предков человека из системы локального биогеоценоза, привел к изменению характера дальнейшей эволюции. Вместе давления системы биогеоценоза, определяющей направление эволюции входящих в нее элементов, человек ставит свою систему представлений, опосредующую его взаимодействие с окружающей действительностью, в значительной степени самостоятельно определяя направление собственного развития. И от степени адекватности господствующих представлений, в том числе, онтологических, от того, позитивно или отрицательно человек относится к реальности, старается ее познать и улучшить или отворачивается от нее, зависит уровень взаимодействия с природой, характер той реальности, которую человек создает и в которой существует.

Системное единство человека и природы существует объективно, но цикл формирования системы «человек и природа» это период, в течение которого человек, являясь субъектом взаимодействия с нею, преодолевает противоречия с природой: зависимость от нее, затем господство над ней, постепенно начиная осознавать свое системное единство с природой. Процесс осознания этого системного единства - это и есть процесс формирования онтологии, как мыслительного обоснования единства мира, которое определяет как поведение отдельного индивида, так и общественную практику. Онтология единство субъективного и объективного по форме, как представления субъекта мышления об объекте, и по содержанию, как проявление адекватности человека, сознающего себя активным элементом системы «человек и природа».

Процесс формирования онтологии является проявлением процесса развития человека, как системы индивида в системе общества и как элемента формирующейся системы «человек и природа». Выявляемая при этом взаимосвязь развития онтологических представлений с развитием системы индивида - с одной стороны, с общественной практикой и уровнем взаимодействия с природой - с другой, полностью подтверждает адекватность используемого системного подхода.

У первобытного человека появившийся разум не противоречит телесной организации, формируя 


\section{Философия и культура 11(71) • 2013}

представления, которые следуют устремлениям, продиктованным инстинктами, опираясь на чувственные образы, закрепленные в рефлексах, разум лишь дополняет их способностью реагировать на своеобразие каждой конкретной ситуации. Это единство разума и телесной организации связано со стабильностью первобытного общества, с единством индивида и коллектива, а также проявляется в единстве человека и природы, которое опирается на представления о «мистическом» единстве со всеми элементами окружающей действительности. Известный исследователь первобытного общества Л. Леви-Брюль описывал их следующим образом: «Для «первобытного» человека, который принадлежит к тотемическому обществу, всякое животное, всякое растение, всякий объект, хотя бы такой, как звезды, солнце и луна, наделен определенным влиянием на членов своего тотема, класса или подкласca, определенными обязательствами в отношении их, определенными мистическими отношениями с другими тотемами и т.д.» ${ }^{1}$. На данном этапе ввиду неразвитости мышления, которое имеет предметный характер и еще не способно к абстрагированию, единство с природой закономерно имеет «мистический» характер, это единство без мыслительного обоснования, т.е. без онтологии. Человек, еще не выделился из природы и не стал автономным субъектов взаимодействия с ней.

На следующем этапе развитие разума приводит к осознанию личных интересов, к повышению активности индивида, растущий индивидуализм которого разрушает первобытное общество. Возросшая при этом автономия разума проявляется в выработке представлений, которые уже не следуют устремлениям, продиктованным инстинктами и рефлексами, а противопоставляются телесной организации, как запреты и ограничения, как нормы морали, дуализм разума и телесной организации проявляется в дуализме представлений.

Дуалистическое взаимодействие разума и телесной организации может и осуществляется в двух вариантах: зависимости разума и его господства. Первоначальный этап зависимости разума проявляется в господстве интересов, продиктованных телесной организацией, которые, будучи индивидуализированы, проявляются в стремлении к богатству, к власти, к телесным наслаждениям. Утилитарный индивидуализм закономерно приводит к разруше-

\footnotetext{
${ }^{1}$ Леви-Брюль Л. Первобытное мышление // Психология мышления / Под ред. Ю. Б. Гиппенрейтер и В.В. Петухова. М.: Изд-во МГУ, 1980. С. 134.
}

нию единства первобытного общества, к нарастанию противоречий, к возникновению неравенства, к иерархическим отношениям доминирования и подчинения. На следующем этапе господство разума над телесной организацией проявляется в его способности к подавлению страстей и пороков путем аскетизма и монастырского существования. Противостояние индивидуализму страстей приводит к господству представлений о неискоренимой порочности и греховности реальной жизни, т.е. к представлениям жизнеотрицания, которые воплощаются в стремлении скрыться от реальности за монастырскими стенами. Дуализм представлений проявляется в дуализме общественной практики.

Человек, осмысливая окружающую действительность, выделяется из природы, но осознает свою зависимость от нее, как от внешних для него объективных, могущественных сил, которые он закономерно обожествляет. Мифологические представления о множестве богов, олицетворяющих природные стихии, постепенно сводятся к противоположным мировым силам: Света и Мрака, Добра и Зла, Бога и Дьявола. Дуализм разума и телесной организации в системе индивида, осознаваемый как противоречия души и тела, аскетической нравственности и господства страстей, связанный с ним дуализм человека и природы, осознаваемый как господство объективных могущественных сил,все это закономерно приводит к возникновению дуалистических религиозных систем представлений, в которых единство мира разрывается: зороостризм, митраизм, христианство и др. Господствовавшее в первобытном обществе циклическое мышление приобретает характер дуалистического, рассматривающего весь мир и человека, в том числе, полем вечной битвы объективных мировых сил.

Выделение человека из природы знаменует разделение субъективного и объективного при явно выраженной иерархии мировых сил над человеком, т.е. объективного над субъективным, возникший и нарастающий разрыв преодолевается с помощью мистицизма веры, как субъективного переживания объективного. Однако в этой иерархии нет единства ни в самом человеке, ни в объективных мировых силах, воспринимаемых как несовместимые и антагонистические противоположности.

Дуализм господствующих представлений определяет дуалистическую логику развития: от крайнего субъективизма индивидуализма страстей к объективизму служения богу с аскетическим подавлением всего телесного и индивидуального. В этом тупике оказались некоторые цивилизации, которые бурно 


\section{Философия науки и образования}

развивались в период господства индивидуализма и пришли в упадок с господством представлений жизнеотрицания, к примеру: Индия, Китай, Монголия, где господствующей религией стал буддизм, ориентирующий на уход от реальности. Дуализм при этом не преодолевается, общественная практика переходит из одной крайности в другую - неадекватность дуализма препятствует развитию.

Непримиримость дуалистического противопоставления представлений начинает преодолеваться во взглядах Платона и, особенно, Аристотеля, где формирующаяся линейность мышления проявляется в постановке вопроса о причине и начале мира, который решается с помощью единого, вечного «сущего». Дуалистические противоположности объединяются в иерархии: мира идей над миром вещей - в системе Платона, вечного единого «сущего» над миром природы - у Аристотеля. «Сущее» понимается Аристотелем не в отрыве от реальности, а является его причиной и истиной, основой единства мира, именно такое понимание и придает этому понятию онтологический статус. Этот уровень мышления, который, опираясь на формирующуюся линейную логику, преодолевает противопоставление противоположностей в единой иерархии представлений, стал основой христианства.

Благодаря унаследованной от античного общества системе представлений христианства, для западноевропейского общества этап господства разума над телесной организацией в системе индивида не стал господством представлений жизнеотрицания. В отличие от других дуалистических религий христианство демонстрирует другой уровень мышления, опирающийся на понятие бога, как абсолютной истины, охватывающей противоположности и стоящей над ними. В этом проявился еще один шаг в развитии абстрактного мышления, благодаря которому понятие бога стало еще более объективным и всеобъемлющим, объединяющим противоположности. В этой единой иерархии представлений противоположности преобразованы в ступени развития: телесного, духовного и божественного, зло - это не мировая сила, а лишь недостаток добра, а дьявол - лишь отпадший на время ангел. Объективное понятие бога, охватывающего добро и зло, реальный мир и потусторонний, стало основой единства представлений, т.е. приобрело онтологический характер. Объединяя противоположности, христианство возвращало человека к реальности, утверждало позитивное к ней отношение, как основу для ее познания и улучшения.

Это единство иерархическое: объективного над субъективным, в котором ничтожности и сла- бости человека соответствует могущество бога. Христианство утверждало иерархию разума над телесной организацией в системе индивида, подавляя страсти, стимулировало развитие разума, преодолевая господство утилитарного индивидуализма. Утверждение иерархии христианских представлений связано с иерархическим мышлением, которое проявляется в общественной практике иерархического феодального сословного общества, которое стабилизируется с утверждением представлений христианства.

Единство христианской иерархии представлений создало условия для преодоления дуализма системы индивида, создавая внешнюю поддержку разуму в его противостоянии с телесной организацией. Постепенно разум в системе индивида окреп, а страсти утратили характер порочности, вследствие этого «душа и тело» от иерархического подавления перешли к диалектическому единству. Формирование системы индивида «душа и тело» завершилось. Онтологическое единство представлений в христианстве позволило выйти из дуалистического тупика и способствовало развитию человека.

Утрата внутренней иерархичности проявилась в разрушении внешней иерархии, чем более человек преодолевал внутренний дуализм, тем становился самостоятельнее, и понятие бога закономерно отодвигалось в сферу потустороннего, трансцендентального - единство иерархии разрушается. Это проявилось в протестантских учениях, где бог трансцендентален и непознаваем, а человек обращен к мирской жизни. Мышление также утратило иерархический характер, что привело к слому феодального общества в процессе буржуазных революций. На основе достигнутого единства «души и тела» стал развиваться рациональный разум, с появлением которого преодолевается зависимость от природы.

Достигнутое преодоление внутренней противоречивости системы индивида и преодоление зависимости от природы закономерно приводит к распространению представлений о единстве мира: пантеизм Н. Кузанского, натурфилософия Р. Декарта, Ф. Бэкона, Ч. Ньютона. К данному этапу относится и учение о бытии Аристотеля, как проявление высшего уровня античной философии, значительно опередившей свое время. Эти онтологические представления являются проявлением этапа, характерного появлением рационального разума, свободного от мистицизма религиозного мышления, при сохранении понятием бога, как абсолютной истины, онтологического значения обоснования единства. Это мыслительное обоснование единства 


\section{Философия и культура 11(71) • 2013}

мира, в котором рациональные представления сочетаются с религиозными, становится основой философии тождества разума и действительности, как возможность и необходимость процесса познания.

На данном этапе формирование онтологических представлений стало возможным благодаря преодолению дуализма объективных сил в понятии абсолютной истины, благодаря которому был преодолен дуализм системы индивида. Однако это единство субъективного и объективного носит промежуточный, иерархический характер, так как еще не опирается на разработанную адекватную систему представлений, а преодолевается, в значительной части, лишь неадекватностью мистицизма веры. Понятие абсолютной истины, стоящей над реальностью, и мистицизм веры неразрывно связаны. Вполне закономерно, что иерархический характер единства просуществовал недолго и уступил место дуализму разума и действительности, субъективного и объективного.

Диалектическое единство разума и телесной организации в системе индивида стало основой дальнейшего развития разума, который приобрел новое качество, закономерно вступив во взаимодействие с ранее сформировавшейся системой «душа и тело». Начался новый цикл формирования системы индивида. Противостояние мистицизму и иррационализму «души и тела» обуславливает характер нового качества разума - это рациональный разум. Развитие разума проявляется в повышении степени его автономии: рациональный разум в меньшей степени связан противостоянием в системе индивида, в большей - обращен на реальную действительность, человек становится субъектом познания и преобразования окружающей действительности, преобразуя ее в объект своей деятельности. Это закономерно приводит к повышению активности индивида, закономерно приводя к новому проявлению индивидуализма в системе общества.

В системе индивида начался новый этап дуалистического противостояния рационального разума и сформировавшейся ранее системы «душа и тело». Рациональный разум, выделившись в элемент системы индивида, закономерно находится в зависимости от ранее сформировавшейся системы «душа и тело», рационализированные представления которой и определяют поведение человека. Дуализм системы индивида проявляется как противостояние рационализированных утилитарных представлений «тела» в виде стремления к наживе и рационализированных представлений «души» в виде трансцендентальной религиозности. На ведущие позиции в обществе выходит индивид буржуазного типа, характерными чертами которого является сочетание разделенных и противопоставленных: утилитарного индивидуализма и трансцендентальной истины.

Нарастающий дуализм системы индивида проявляется в дуализме господствующих представлений, в том числе, философских. В эпоху Нового времени бог еще рассматривается как основа единства, но уже в философии И. Канта дуализм принимает завершенный характер: бог - «мудрый правитель» «умопостигаемого мира», противопоставленного «чувственно воспринимаемому» миру природы. На этом этапе противостояния рационального разума и системы «душа и тело», проявившегося в противопоставлении разума и действительности, субъекта и объекта, духовной и материальной субстанций, понятие бога стало трансцендентальным и закономерно утратило онтологический характер обоснования единства. Растущий субъективизм утилитарного индивидуализма закономерно связан с усилением объективизма трансцендентальности.

В условиях разорванности картины мира, в которой одна часть противопоставляется другой, философские понятия, которыми ранее обосновывалось единство, также утрачивают свой онтологический статус. У М. Хайдеггера бытие - это противопоставленное реальности трансцендентное: «Бытие не есть нечто из реального» ${ }^{1}$. Бытие трансцендентализма утратило характер обоснования единства мира, стало категорией отвлеченного философствования о трансцендентальном. Сама философия у М. Хайдеггера отделена от реальности, как «нечто самостоятельное, последнее», определяемое «только через саму себя и в качестве самой себя» ${ }^{2}$. Понятие бытия утрачивает статус предельной категории, обоснования единства мира, представление о разорванности мира определяет раздробленность бытия. Отрыв разума от действительности закономерно проявляется в неадекватности представлений.

Дуализм рационального разума и системы «душа и тело» в системе индивида, связанный с ним дуализм представлений о разделенных «мирах» вновь привели к состоянию дуалистического тупика, в котором выбор представляется между господством утилитарного индивидуализма и объективизмом трансцендентальности истины, нравственности, бытия. На этапе зависимости рационального разума

\footnotetext{
${ }^{1}$ Хайдеггер М. Основные понятия метафизики // Вопросы философии. 1989. № 9. С. 116-122.

2 Хайдеггер М. Тезис Канта о бытии // Философия Канта и современность. Сборник переводов. Ч. 2. М., 1976. С. 25.
} 


\section{Философия науки и образования}

от системы «душа и тело» поведение человека определяет активность утилитарного индивидуализма, на следующем этапе господства рационального разума - пассивность и жизнеотрицание трансцендентализма.

Шаг к единству дуалистических противоположностей делается на следующем этапе господства рационального разума над системой «душа и тело» в системе индивида. Данный этап характерен появлением двух альтернативных, взаимоотрицающих и взаимообусловленных систем представлений: идеализма и материализма. Обе эти системы представлений делают шаг в сторону онтологии, пытаясь преодолеть дуализм объективности и субъективности путем выстраивания противоположных иерархий: духа над природой или материи над сознанием. При этом идеализм выносит единство мира за рамки реальной действительности, в область «абсолютного духа»: «только бог есть истинное бытие» Г.В.Ф. Гегель ${ }^{1}$. Идеализм делает шаг в развитии мышления, которое становится диалектическим, но применение диалектики ограничено сферой духа, противопоставленной миру природы. Идеализм, обосновывая трансцендентальность разума, противопоставленного реальной действительности, лишь стабилизирует их дуалистическое разделение и противопоставление.

Идеалистическое мировоззрение обуславливает логику дуалистического тупика, обусловленного противопоставлением одной части реальности другой: либо релятивизм субъективизма, либо трансцендентализм, который в принципе непознаваем; либо аморальность утилитарной практики, либо оторванная от реальности трансцендентальная нравственность. Идеалистическое мировоззрение становится основой этики духовного самосовершенствования, стимулируя пассивность в практической деятельности, отрешенность от реальности, жизнеотрицание. К примеру, Г. Марсель пишет о потребности в «бытии», «чтобы все не свелось к поверхностной игре внешних сил, изменчивых и несостоятельных» ${ }^{2}$.

В дуализме идеалистических представлений рациональный разум связан с утилитарностью и прагматизмом индивидуализма, что приводит к его

\footnotetext{
${ }^{1}$ Гегель Г.В.Ф. Энциклопедия философских наук. Т. 1. Наука логики. М.: Мысль, 1974. 452 с. (Филос. наследие. Т. 63). С. 53; 424 c. С. 171.

${ }^{2}$ Марсель Г. Онтологическое таинство и конкретное приближение к нему // Марсель Г. Трагическая мудрость философии. М., 1995. С. 77.
}

дискредитации, к усилению представлений «души и тела»: мистицизма религиозной веры, иррационализма телесных потребностей, что проявляется в культе секса, комфорта, растущего потребления.

Материализм выстраивает противоположную иерархию представлений, отстаивая единство мира на основе его материальности (К. Маркс). Материалистическое мировоззрение более рационально, так как строится на подавлении представлений «души и тела», отрицая как религиозный трансцендентализм, так и утилитарность индивидуализма, опирается на рациональный разум, направляя его на познание и творческое преобразование действительности. Материализм делает еще один шаг на пути преодоления разрыва объективной истины и практической деятельности. Объективная истина в материализме максимально приближена к реальности, как руководство по ее преобразованию. Идея коммунизма - это рационально разработанная цель, которая вызывает большее доверие и веру, в которой проявляется влияние системы «душа и тело» в системе индивида. Иерархия вновь обретает единство, в котором рациональное мировоззрение становится объектом веры.

Мышление приобретает иерархический характер, в общественной практике это проявляется в господстве буржуазии или диктатуре пролетариата. Дуализм противоположных систем представлений проявляется в дуализме общественной практики в виде противостояния капитализма и социализма.

Взаимозависимость и взаимообусловленность идеализма и материализма проявляются не только в противоположном решении одних и тех же вопросов, но и в том, что каждая из этих противоположностей порождает другую. Господство идеалистической идеологии порождает утилитарность и вульгарный материализм в практической деятельности, господство материализма порождает идеализм в практике социалистического общества, где стремление к наживе подавлялось, стремление к материальным благам преследовалось и порицалось, добродетелью считалось бескорыстное служение народу, стране, идее коммунизма. У нас было «духовное» общество, стимулирующее разум в системе индивида, создававшее условия для его ускоренного развития.

И идеализм, и материализм можно рассматривать как шаг к построению новой онтологии, в которой основой единства становится одна из противоположностей, значение которой абсолютизируется. Линейность мышления, опирающегося на представление об абсолютности истины, проявляется в стремлении к определению предельных категорий, 


\section{Философия и культура 11(71) • 2013}

вместо «сущего», «бытия» идеализм называет «абсолютный дух» (Г.В.Ф. Гегель), материализм - материю. Но иерархический характер единства не позволяет охватить мир и человека в их полноте и целостности, система представлений строится на отрицании противоположной, противопоставляя одну часть реальности другой, не преодолевает противоречия, а выстраивает иерархические отношения доминирования и подчинения, оставаясь во власти тех же противоречий. В практической деятельности линейность мышления проявляется во власти противоречий над человеком, противопоставляющим одну часть действительности другой, как истинное и ложное, стремящимся навязать собственные взгляды и образ жизни другим, пытающимся строить отношения доминирования и подчинения.

Дуализм идеалистической системы представлений, в которой утилитарный индивидуализм на практике противопоставлен трансцендентальности истины, определяет логику развития западного общества: от остроты противоречий, порождаемых индивидуализмом, к отрешенности от реальности трансцендентализма, к пассивности жизнеотрицания. Эта логика развития полностью подтверждается историей западного общества. Бурное развитие в период господства утилитарности индивидуализма в системе индивида сопровождается обострением противоречий: межличностных, конкурентных, классовых, национальных, межгосударственных, на этом этапе господство человека над природой, как проявление субъект - объектных отношений, оборачивается хищнической эксплуатацией ее ресурсов. Переход к этапу господства рационального разума позволяет преодолеть эти противоречия или снизить их остроту, но приводит к господству представлений трансцендентализма, к отрешенности от реальной жизни, к жизнеотрицанию, что проявляется в нарастающей пассивности и упадке западного общества.

Дуализм идеалистических представлений связан с дуализмом мышления, не способного охватить человека и мир природы в их целостности, в единстве противоположностей. В западной философии это проявляется в неспособности преодолеть противопоставление разума и действительности, рациональности и иррациональности, науки и культуры, объективизма и субъективизма, «бытия» и единичного существования индивидуальности. В этом порочном круге: от трансцендентализма - к субъективизму и обратно, второе столетие беспомощно вертится западная философия.

Благодаря единству материалистической иерархии представлений, служившей опорой для подавле- ния мистицизма и иррациональности «души и тела в системе индивида, российское общество избежало состояния дуалистического тупика, преодолело отставание от западноевропейского и шагнуло в своем развитии вперед. Материалистическая система представлений преодолевает разрыв разума и действительности, подавляя иррационализм и мистицизм, выдвигает цели, подлежащие реализации в реальной действительности. Сохраняющаяся линейность мышления проявляется в понимании развития, как объективного хода истории, как проявление стоящей над реальностью абсолютной, объективной истины.

Сохраняющееся влияние системы «душа и тело» проявляется в религиозном отношении к рациональному мировоззрению, которое становится объектом веры. По отношению в религиозному мышлению характер веры меняется, иерархическое религиозное мышление абсолютизирует личность, иерархическое рационализированное мышление абсолютизирует мировоззрение или «ценности», что позволяет критически оценивать отдельные личности. И в идеализме и материализме сохраняется иерархическая структура мировоззрения: идеи над реальностью, отличие в том, что материалистическая иерархия, как в свое время христианская, объединяет противоположности в единой иерархии. Трансцендентальность истины в идеализме предоставляет полную свободу утилитарности индивидуализма на практике, в материализме близость объективной истины, которая субъективно переживается, становится основой подавления утилитарности индивидуализма и мистицизма религиозности. Цель построения коммунизма - это рациональная цель, подлежащая воплощению в реальной действительности. Вера в такую цель побуждает активность в реальной жизни, направляет разум на ее познание и преобразование.

Первоначальный период истории Советского Союза - это период религиозной веры в вождей, которая постепенно с развитием рационального разума трансформировалась в веру в рациональное материалистическое мировоззрение. Рациональный характер господствующей в обществе материалистической системы представлений создал условия для ускоренного развития системы индивида, стимулируя развитие разума. Однако закономерным проявлением развития рационального разума стала утрата веры в 70-х годах XX века. Цель построения коммунизма стала рассматриваться как вопрос далекого будущего, она стала приобретать характер оторванности от реальной действительности, трансцендентальности - иерархия представлений стала распадаться. 


\section{Философия науки и образования}

Системное рассмотрение человека и общества позволяет лучше понять характер кризиса, который переживает западное и российское общество. Кризис западного общества - это кризис рационального разума, поставленного на службу утилитарности, что влечет за собой усиление иррациональности субъективизма и мистицизма трансцендентализма. Кризис российского общества - это кризис веры, вследствие развития разума, который в процессе осмысления господствующей идеологии и поставленных ею «объективных» целей, выявляет их неадекватность, отрыв от реальной действительности.

Новое качество системы индивида российского общества проявляется в отказе от противопоставления и отрицания, на которых строится идеалистическая и материалистическая системы представлений. Мы вышли из этой системы противоречий, мы более не противопоставляем идеализм и материализм, капитализм и социализм, личность и общество, права и обязанности, не делим наших предков на «красных» и «белых», выделяя тех, кто честно служил стране и народу, в общественной практике мы синтезируем рыночный механизм и социальную направленность государства. Рациональное мировоззрение перестало быть объектом веры, а стало основой для самостоятельного осмысления действительности. Это отсутствие отрицания свидетельствует о том, что в системе индивида российского общества рациональный разум от противостояния с системой «душа и тело» и иерархического господства над ней перешел к диалектическому единству, что проявляется в нарастающей системности мышления. Новое качество мышления, утратившего иерархический характер, проявилось в общественной практике разрушения иерархического политического режима во главе с КПСС. Это новое качество разума создает условия для преодоления дуализма представлений в системном мировоззрении, как основы снятия противоречий в обществе, противостояния с природой.

Онтология на данном этапе развития - это адекватная система представлений, как единство субъективного и объективного, гармонизирующая систему индивида, систему общества и взаимодействие человека и природы, охватывающая их в системном единстве.

Онтологические представления, как мыслительное обоснование единства мира, закономерно являются проявлением уровня качества человека, проявляемого в уровне взаимодействия с природой. Человек не может осуществлять господство над природой, сознавая единство с ней, также как не может быть в единстве с природой, исповедуя противопоставление с нею. Единство с природой - это единство качества человека, руководствующегося представлениями о единстве с природой, и общественной практики, строящейся в соответствии с этими представлениями. В силу этого очевидного правила соответствия онтология на этапах зависимости от природы и господства над ней из учения о единстве мира закономерно стала учением о категории бытия, противопоставленной реальности, затем об «абсолютном духе», стоящим над природой, или о материи, стоящей над сознанием. Внутренняя противоречивость человека, дуализм и неадекватность его представлений и противостояние с природой взаимообусловлены. Вопрос о единстве мира встает в настоящее время в связи с достижением нового уровня качества системой индивида российского общества, переходящего к этапу единства с природой.

\section{Список литературь:}

1. Абдуллин А. Р. Онтологическое мышление: виды и сущность. Уфа: Изд-е Башкирск. ун-та, 2002.481 с.

2. Аристотель. Метафизика // Хрестоматия по западной философии:

Античность. Средние века. Возрождение. М.: Астрель: АСТ, 2003. 800 с.

3. Биофилософия / научн. рук. И. К. Лисеев, отв. ред. А. Т. Шаталов. М., 1997. 264 с.

4. Гегель Г.В.Ф. Энциклопедия философских наук. Т. 1. Наука логики. М.: Мысль, 1974. 452 с.

5. Доброхотов А. Л. Категория бытия в классической западноевропейской философии. М.: Изд-во Московского университета, 1986.

6. Исторические типы рациональности. / Отв. ред. В. А. Лекторский. Т. 1. М., 1995. 350 с.

7. Леви-Брюль Л. Первобытное мышление //

Психология мышления / Под ред. Ю. Б. Гиппенрейтер и В. В. Петухова. М.: Изд-во МГУ, 1980. С. 130-140.

8. Марсель Г. Онтологическое таинство и конкретное приближение к нему //

Марсель Г. Трагическая мудрость философии. М., 1995. С. 72-106.

9. Физика в системе культуры / Отв. ред. Ю. В. Сачков. М., 1996. 231 с.

10. Хайдеггер М. Основные понятия метафизики // Вопросы философии. 1989. № 9. С. $116-122$. 


\section{Философия и культура 11(71) • 2013}

11. Хайдеггер М. Тезис Канта о бытии //

Философия Канта и современность. Сборник переводов. Ч. 2. М., 1976. С. 18-25.

12. Шагиахметов М. Р. Основы системного мировоззрения. Системно-онтологическое обоснование.

M.: КMK, 2009. 263 c.

\section{References (transliteration):}

1. Abdullin A. R. Ontologicheskoe myshlenie: vidy i sushchnost». Ufa: Izd-e Bashkirsk. un-ta, 2002. 481 s.

2. Aristotel». Metafizika // Khrestomatiya po zapadnoi filosofii: Antichnost». Srednie veka. Vozrozhdenie. M.: Astrel': AST, 2003. $800 \mathrm{s.}$

3. Biofilosofiya / nauchn. ruk. I. K. Liseev, otv. red. A. T. Shatalov. M., 1997. 264 s.

4. Gegel» G.V.F. Entsiklopediya filosofskikh nauk. T. 1. Nauka logiki. M.: Mysl», 1974. 452 s.

5. Dobrokhotov A. L. Kategoriya bytiya v klassicheskoi zapadnoevropeiskoi filosofii. M.: Izd-vo Moskovskogo universiteta, 1986.

6. Istoricheskie tipy ratsional'nosti / Otv. red. V. A. Lektorskii. T. 1. M., 1995. 350 s.

7. Levi-Bryul» L. Pervobytnoe myshlenie // Psikhologiya myshleniya / Pod red. Yu.B. Gippenreiter i V. V. Petukhova. M.: Izd-vo MGU, 1980. S. 130-140.

8. Marsel» G. Ontologicheskoe tainstvo i konkretnoe priblizhenie k nemu // Marsel» G. Tragicheskaya mudrost» filosofii. M., 1995. S. 72-106.

9. Fizika v sisteme kul'tury / Otv. red. Yu.V. Sachkov. M., 1996. 231 s.

10. Khaidegger M. Osnovnye ponyatiya metafiziki // Voprosy filosofii. 1989. № 9. S. 116-122.

11. Khaidegger M. Tezis Kanta o bytii // Filosofiya Kanta i sovremennost». Sbornik perevodov. Ch. 2. M., 1976. S. 18-25.

12. Shagiakhmetov M. R. Osnovy sistemnogo mirovozzreniya. Sistemno-ontologicheskoe obosnovanie. M.: KMK, 2009. $263 \mathrm{~s}$. 